\title{
Predicting Vehicle Loads Variation with Road Profiles and Vehicle Characteristic
}

\author{
Rosnawati Buhari $^{1+}$, Saifullizam Puteh ${ }^{2}$, Munzilah Md Rohani ${ }^{1}$ and Basil David Danial ${ }^{1}$ \\ ${ }^{1}$ Smart Driving Research Centre, Faculty of Civil and Environmental Engineering, Universiti Tun Hussien \\ Onn Malaysia, 86400, Parit Raja, Batu Pahat, Johor. \\ ${ }^{2}$ Faculty of Technical and Vocational Education, Universiti Tun Hussien Onn Malaysia, 86400, Parit Raja, \\ Batu Pahat, Johor.
}

\begin{abstract}
Determination of the dynamic response of continuous road pavements made of asphalt (or concrete to moving dynamic loads is very important in pavement design as it helps engineers to predict road damage. This paper reveals the characteristic of the dynamic wheel loads pattern produced by the various road surface profiles, vehicle speed, suspension types. Road Profiles were generated based on the theory by Rabson and also Hardy and Cebon. As a result, the response of the vehicle subjected to the road profiles level of roughness is significant. The Dynamic load coefficient of the forces from travelling vehicles on the roads with higher International Roughness Index value result is higher as been expected. The value of the standard deviation indicated that the amplitude of vibration from an axle fitted with steel suspension is bigger than other suspension type. Higher International roughness index value was increased the axle loading and it is worse for steel suspension rather than air suspension.
\end{abstract}

Keywords: dynamic wheel loads, q-truck model, road profile, international roughness index

\section{Introduction}

Irregularities in pavement profiles excite a vehicle as it travels along the road, causing continuous changing tyre forces [1]. The dynamic behavior of heavy vehicle axles fitted with wheels mounted with instrumentation and found that dynamic loading patterns on a road surface are very similar for the same vehicle at the same speed. At low speed, vehicle vibration is slight, but high-speed motions lead to significant vehicle vibrations that generate additional inertia forces. The increase in dynamic loads with speed is compensated for by the shorter duration of an applied axle load at increased speed. Tyre forces or dynamic wheel loads also dependence on other several factors including vehicle characteristics; e.g. masses, static gross weight and axle loads, suspension type and conditions, tyre and wheel dimension, etc.; as well as travelling conditions of the vehicle; e.g. speed, horizontal acceleration, lateral position on the traffic lane, etc. [2-3]. The investigation of the quantitative influence of surface roughness, speed and vehicle parameters result that vehicle speed has a significant effect on power spectral density (PSD) of loads [4]. The increased dynamic loads with speed can then increase theoretical road damage significantly. It is also found that a rough pavement with a pavement serviceability index (PSI) of 2.5 experienced damage approximately $50 \%$ greater than that of a smooth road for most typical truck suspensions [5].

\section{Vehicle Roan Interaction}

This point of view was verified in the work of Hardy and Cebon who examined the importance of structural dynamics in the primary response of a flexible pavement to fluctuating, moving wheel loads by means of a quarter-vehicle model [6-7]. The allowable total weight of the axle is 3 tonnes represents a Heavy

${ }^{+}$Corresponding author. Tel.: +6074564375.

E-mail address: rosna@uthm.edu.my. 
Goods Vehicles (HGVs) of the commercial vehicle. A two-degree of freedom model of a truck with a simple suspension system moves at constant speed along a rough surface. In accordance, the suspension force is given by the differential equation:

$$
m_{g} z_{1}=-c_{1}\left(\tilde{z}_{1}-z_{2}\right)-k_{1}\left(z_{1}-z_{2}\right)
$$

Similarly the tyre forces imposed on each tyre element can be written as:

$$
m_{u} \ddot{z}_{2}=c_{1}\left(\tilde{z}_{1}-\tilde{z}_{2}\right)+k_{1}\left(z_{1}-z_{2}\right)+c_{2}\left(\tilde{z}_{a}-\tilde{z}_{2}\right)+k_{2}\left(z_{a}-z_{2}\right)
$$

Where $m_{g}$ is sprung mass, $m_{\mathrm{u}}$ is unsprung mass, $k_{1}$ is suspension stiffness, $c_{1}$ is suspension damping, $k_{2}$ is tyre spring, $\varepsilon_{2}$ is tyre damping and $z_{1}$ and $z_{2}$ are absolute displacements of the body and the wheel, respectively. Single dots and double dots above the symbols represent first, (velocity) and second, derivative processes (acceleration), respectively. i.e., the velocity process $d y / d t$ and the acceleration process, $d^{2} y / d t^{2}=\ddot{y}$. The frequency response equation of this vibration system has a simple expression in three matrices, $A_{s} B$ and $C$ of the standard state-space equation:

$$
\begin{gathered}
\tilde{z}=A z+B u \\
y=C z
\end{gathered}
$$

The $u$ is the height of pavement surface irregularities. For an $n t h$-order system, $A$ is an $\left[\begin{array}{lll}n & n]\end{array}\right]$ system matrix (in this case $n=4$ ), $B$ is [ $n \times 1$ 1] column vector of inputs, $C$ is an $[m \times n]$ output matrix

\section{Methodology}

This task aims to uncover the profiles of dynamic wheel loads generated by the trucks travelling on different road profiles and evaluate the DLC of the load throughout a various factor that influence it. The vehicle was simplified into a vehicle model. A two-degree of freedom model of a truck with a simple suspension system moves at constant speed along a rough surface are used to simulate the vehicles. This quarter truck model was used rather than half or whole vehicle models for simulating the real operating conditions of the vehicle fleet. Even though it is much more simple than the half ore whole truck model that excluding the detailed suspension non-linearity and complexities of body mass motions that are typical for heavy vehicles, the frequency content of the dynamic loads is sufficiently realistic for the purpose of the study to uncover pavement response. Moreover, it was efficiently identified for use with personal computers to predict pavement loading [8-13].

The matrix of acceleration for the quarter truck described above was build into the MATLAB software. The input to the quarter truck model was a single sided spectrum of road displacement. In accordance, a longitudinal profile of the pavement influenced the vertical excitation of the vehicle and the degree to which the sprung mass and axle motions causing dynamic loading was produced. The surface characters of the roads are considered deviation of the road from the simplest possible case perfectly smooth, horizontal and straight. The profile was described as the change in elevation of the pavement surface with distance or in terms of the dominant wavelengths in the profile and their amplitude of power spectral density (PSD) of the profile.

\subsection{Generation of Single Load Profile}

Two-dimensional random profiles may be generated by applying a set of random phase angles, uniformly distributed between 0 and $2 \pi$ to a series of coefficients derived from the desired direct spectral density. One possible way of partitioning the wavelengths as given in Table 1. In accordance, wavelengths from $1 \mathrm{~m}$ to $50 \mathrm{~m}$ for the vehicle speed at $20 \mathrm{~m} / \mathrm{s}$ known as undulations deals primarily with suspension and stimulates a dynamic response. This includes the basic sprung mass resonance at about $1 \mathrm{~Hz}$, which must be controlled by the damping. Wavelengths of $0.01 \mathrm{~m}$ to $1 \mathrm{~m}$ deal largely with tyre deflection and again, require a dynamic analysis of the vehicle response. For wavelengths under $0.01 \mathrm{~m}$, there is little dynamic response from the vehicle with the force period being under $0.5 \mathrm{~ms}$. Typical results of surface displacement profiles were generated with data points whereby every $0.1 \mathrm{~m}$ gave a lower wavelength limit, in correspondence to the Nyquist frequency of $0.2 \mathrm{~m}$ and where the upper wavelength limit was several hundred metres. 
The corresponding series of spot heights $u_{x}$ at regular intervals along the track is obtained by taking the inverse Discrete Fourier Transform (DFT) of the spectral coefficients. Most experimental measurements of random processes are carried out digitally. Typical samples are measured at a series of regularly spaced times. The time series analysis is used to determine the spectral estimates of the original function by analysing the discrete time series obtained by sampling a finite length of a sample function and employing a Fourier transform. The discrete value of the series is carried out by using an inverse Fourier transform.

\subsection{Power Spectral Density (PSD)}

Power Spectral Density of the profile height is used to characterize the amplitude and wavelength of roads where the road is considered a homogeneous, isotropic random process with a Gaussian distribution. Even though roads are not completely homogeneous, certain sections of a road are found to be stationary and this assumption was found to be generally applied. The slope of the PSD was found to be independent of road surface, but a function of the root-mean square (RMS) of the road roughness. The International Roughness Index (IRI) is a common method to describe roughness that is proposed by World Bank as a measure on road smoothness in early 1980a. It is based on quarter car vehicle model and has been widely accepted as a standard statistic of road roughness in many countries. Using IRI, Hardy and Cebon found that roughness coefficient correlated with the IRI [6].

\section{Results and Discussion}

\subsection{Dynamic wheel loads}

Figure 1 shows result generated from the first case with nine independent runs of $500 \mathrm{~m}$ road simulation using variables supplied in Table 2. It gives the parameters variation for 9 road profiles where: road 1-6: the random seed number was changed; road 7-9, the random seed number and wavelengths are the same but the IRI is varied. The IRI for new pavement is about 1.5-3.5. In a practical sense, however, IRI is usually equal to or greater than 2 .

The height of surface profile, representing pavement roughness, is a function of spatial distance along the pavement. The sample interval for all road profiles is $0.1 \mathrm{~m}$. The results show that the random seed number has significant influence on the road profile. Using the same random seed number of 33 but with a differentiated IRI, results prove that by changing the IRI from 2 to 3.5 , the displacement at the lower road level increases and the range between the lowest and the highest displacement is raised.

Figure 2 only shows forces generated by single axles. Generally, as shown in the figures, loading from the vehicles fitted with steel suspensions is significantly higher and more non-uniform compared to the forces generated by the vehicles fitted with air suspension. It shows that the amplitudes quickly increase at certain locations due to the body bounce modes through immediate up/down levels of road surface. Analysing the forces statistically, the standard deviation of the forces generated by the single axle-steel suspension ranges between 3.18 and 5.57; that is, for the forces generated by single axle with steel suspension travelling on Road 1 and Road 9, respectively. These can be compared to the standard deviation of forces generated by the SINA which ranges between 2.10 and 3.68 on the same roads. The standard deviation of the forces generated by the STEERS, though were found to be in-between the standard deviations computed for SINS and SINA.

Table 1. Road Spectral analysis

\begin{tabular}{|l|c|c|}
\hline Characteristic & Wavelength $(\mathrm{m} /$ cycle $)$ & Influence on \\
\hline $\begin{array}{l}\text { Slopes } \\
\text { Material }\end{array}$ & $\begin{array}{c}50 \mathrm{~m}<\lambda \\
\text { Molecular }\end{array}$ & Pseudo-static \\
\hline Undulations & $1 \mathrm{~m}<\lambda<50 \mathrm{~m}$ & Dynamic (ride) \\
\hline Roughness & $0.01 \mathrm{~m}<\lambda<1 \mathrm{~m}$ & Dynamic \\
\hline Texture: & & \\
- Macro & $0.001 \mathrm{~m}<\lambda<0.01 \mathrm{~m}$ & Friction \\
\hline Material & $10 \mu \mathrm{m}<\lambda<0.001 \mathrm{~m}$ & Friction \\
\hline
\end{tabular}


The same phenomenon happens for dual and tridem axles; axles fitted with steel suspensions significantly increased the tyre bounce from the road surface especially on the roads with the highest IRI values. In this condition, the standard deviation of the forces from DUAS is approximately 5.53 that is the highest value among them. It is followed by SINS and TRIS. The lowest standard deviation is 1.21 for the TRIA travelling on Road 4, IRI=2. The standard deviation of the other forces is given in Table 2.

\subsection{Dynamic Load Coefficient}

The dynamic load coefficient of differing lengths of road has been computed to discover their effect on dynamic load behavior. Figure 3 illustrates the DLC values from the STEER axle travelling along 100m, $300 \mathrm{~m}$ and $500 \mathrm{~m}$ on Road 9 . As shown in the figure, extended road lengths from $100 \mathrm{~m}$ to $300 \mathrm{~m}$ and $500 \mathrm{~m}$ changed the pattern of DLC results for vehicle speeds ranging from 10 to $30 \mathrm{~m} / \mathrm{s}$. In comparison, the DLC values for the force of the vehicles travelling at $10 \mathrm{~m} / \mathrm{s}$ to $30 \mathrm{~m} / \mathrm{s}$ increased continuously for roads that were $300 \mathrm{~m}$ and $500 \mathrm{~m}$ long. The same pattern was found for other road profiles (see Figure 4). The DLC of the forces from travelling vehicles on the roads that have higher IRI value result in higher than expected.

The same results were found for speed variations, showing an increase with increasing vehicle speeds except that at a vehicle speed of $30 \mathrm{~m} / \mathrm{s}$, the DLC value decreased when the vehicle travelled at a speed of $30 \mathrm{~m} / \mathrm{s}$.

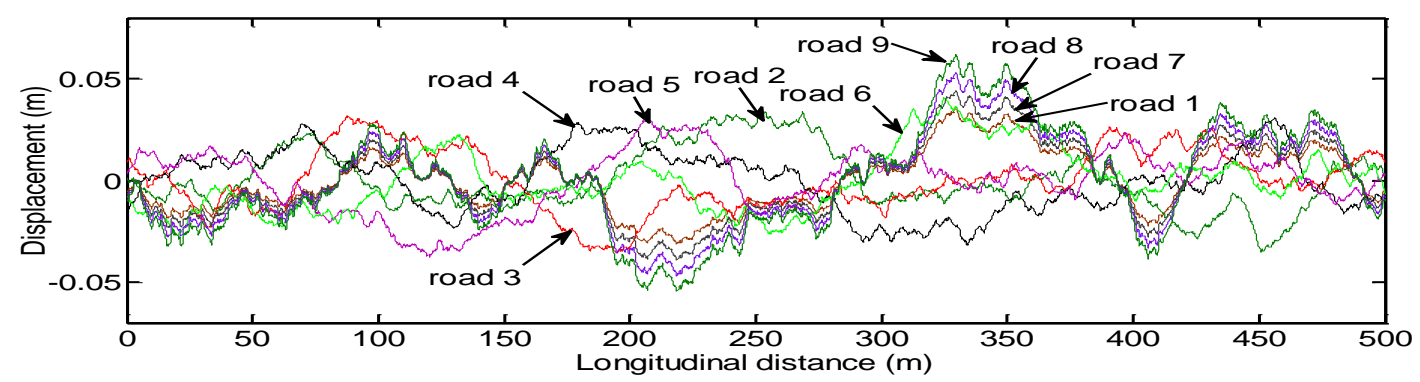

Fig. 1: Road profiles.

Table 2. Standard deviation of the forces

\begin{tabular}{|c|c|c|c|c|}
\hline Road & IRI & steer & $\begin{array}{c}\text { Single axle with steel } \\
\text { suspension }\end{array}$ & $\begin{array}{c}\text { Single axle with air } \\
\text { suspension }\end{array}$ \\
\hline 1 & 2 & 2.43 & 3.18 & 2.10 \\
\hline 2 & 2 & 2.36 & 3.82 & 2.15 \\
\hline 3 & 2 & 3.25 & 4.56 & 2.51 \\
\hline 4 & 2 & 1.65 & 3.23 & 2.12 \\
\hline 5 & 2 & 2.16 & 3.19 & 2.10 \\
\hline 6 & 2 & 2.61 & 4.16 & 2.46 \\
\hline 7 & 2.5 & 3.03 & 3.98 & 2.62 \\
\hline 8 & 3 & 3.63 & 4.78 & 3.15 \\
\hline 9 & 3.5 & 4.24 & 5.57 & 3.68 \\
\hline
\end{tabular}

These can be compared to the standard deviation of forces generated by the singe axle-air suspension which ranges between 2.10 and 3.68 on the same roads. The standard deviation of the forces generated by the steer axle, though were found to be in-between the standard deviations computed for single axle with steel suspension and single axle with air suspension. Also shown in the figure for the same IRI=2, dynamic loads increasing approximately $10 \%$ to $35 \%$ of the static loads, depends on the suspension type. Increasing the road roughness was then higher the dynamic load to about $50 \%$ increases. This is partly because of dynamic bouncing influenced by the design of the vehicle suspension. It is clear that there are large differences between the dynamic loads under different types of suspension, with air suspensions always producing lower dynamic load coefficient than steel suspensions.

For the impact to road wear, the process that cause road wear are extremely complicated and only some of them are affected by the vertical loads applied to the road surface. Although, as an approximation, it is usually assumed that, these higher loads will increase the road wear particularly by heavy good vehicles. A summary of the maximum DLC value of tyre forces from all vehicles is listed in Table 3 . They include the 
conditions that influence forces such as loading conditions, road length, vehicle speed, road roughness and road profiles.

Table 3: Varied parameters for 9 road profiles

\begin{tabular}{|c|c|c|c|}
\hline Road No. & $\begin{array}{l}\text { Random seed } \\
\text { number, } R s\end{array}$ & IRI & Pavement type $(5,11)$ \\
\hline 1 & 33 & 2 & \multirow{6}{*}{$\begin{array}{l}\mathrm{C}=6.76 \times 10^{-13} \text { ], Pavement type : motorway or principal road, Road } \\
\text { classification: A (very good) }\end{array}$} \\
\hline 2 & 927711160 & 2 & \\
\hline 3 & 364849192 & 2 & \\
\hline 4 & 204957605 & 2 & \\
\hline 5 & 638580085 & 2 & \\
\hline 6 & 547070247 & 2 & \\
\hline 7 & 33 & 2.5 & $\begin{array}{l}\mathrm{C}=10.5625 \times 10^{-8}, \text { Pavement type: motorway or principal road. Road } \\
\text { classification: B (good) }\end{array}$ \\
\hline 8 & 33 & 3 & $\begin{array}{l}\mathrm{C}=15.21 \times 10^{-8}, \text { Pavement type: motorway or principal road. Road } \\
\text { classification: B (good) }\end{array}$ \\
\hline 9 & 33 & 3.5 & $\begin{array}{l}\mathrm{C}=20.7025 \times 10^{-8}, \text { Pavement Type: motorway or principal road. Road } \\
\text { classification: } \mathrm{B} \text { (good) }\end{array}$ \\
\hline
\end{tabular}

It is observed that the result may be separated into two parts -higher and lower DLC values. As seen in the Table 3 the higher DLC value are found from forces generated from vehicles fitted with steel suspension compared to vehicles fitted with air suspension. Also seen from the table, for all vehicle model, the DLC value of generated force from DUAS with a $1 / 3$ load travelling at $30 \mathrm{~m} / \mathrm{s}$ on Road 9 is always higher than in the other cases. Furthermore, road length is found to not impact DLC value very much.

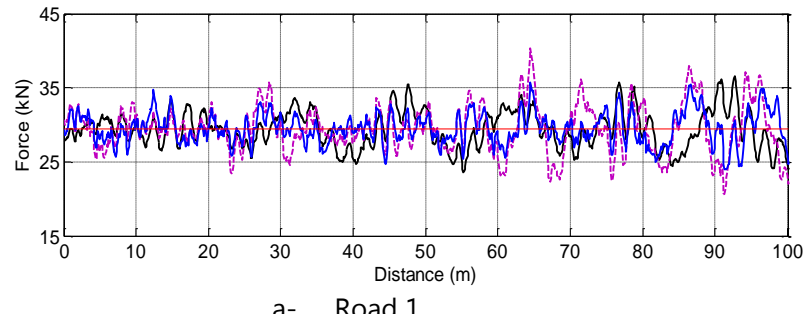

a- $\operatorname{Road} 1$

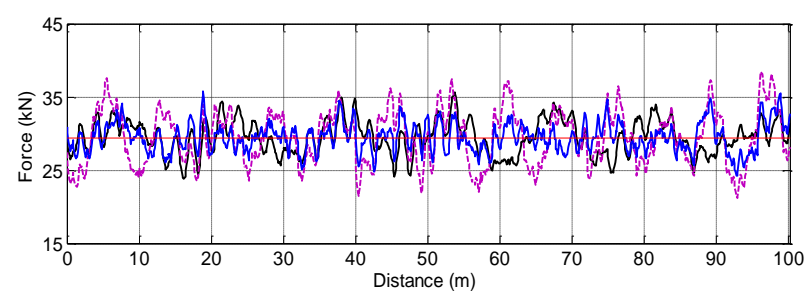

b- Road 2

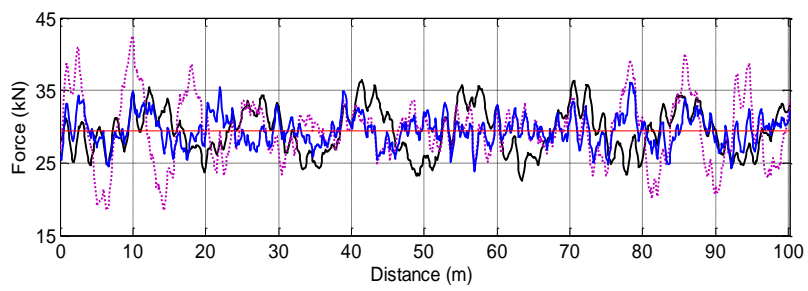

c- Road 3

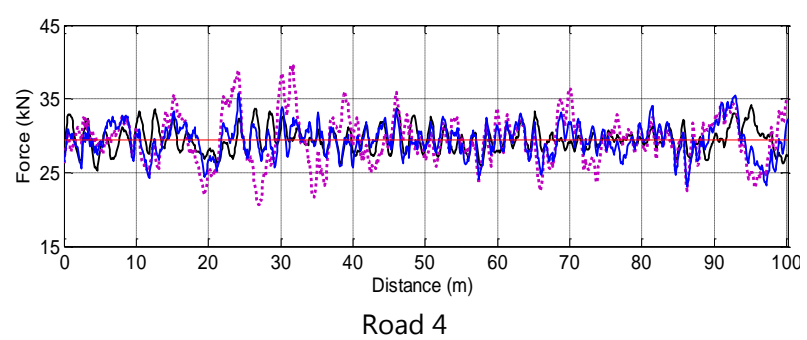

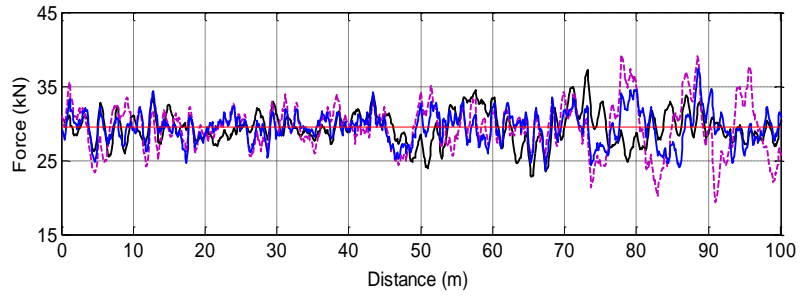

d- Road 5

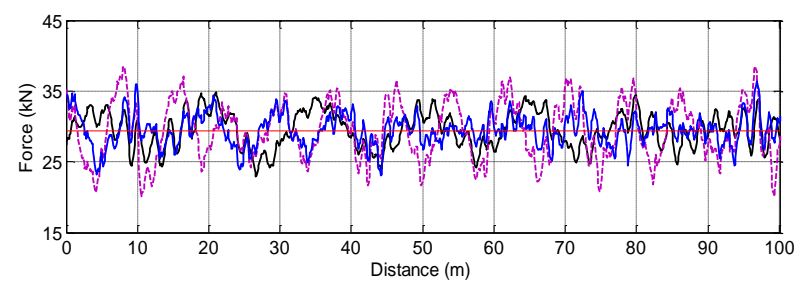

f- $\quad$ Road 6

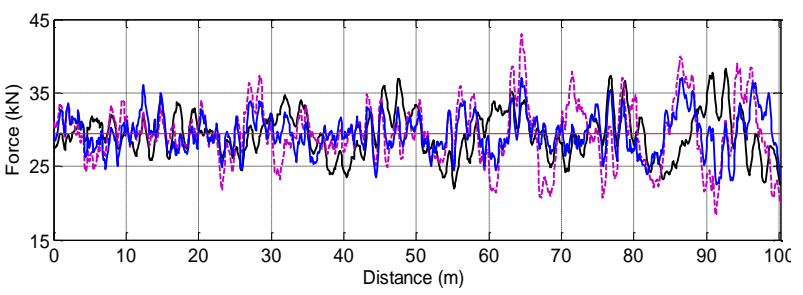

g- $\quad$ Road 7

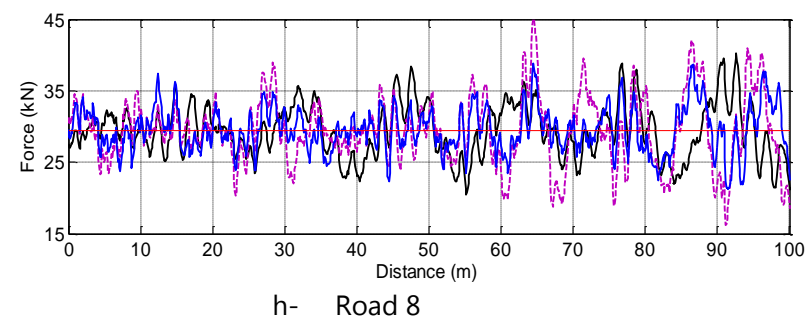

h- Road 8 


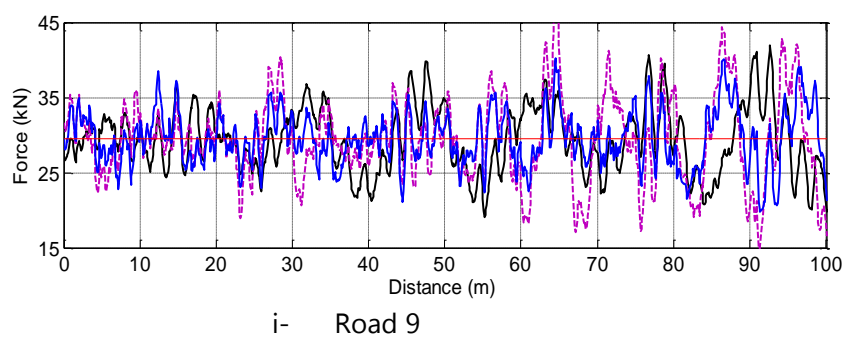

Fig. 2: Tire forces of Quarter truck of steer axle, single axle-steel suspension and single axle-air suspension [black-smooth line=steer axle, blue-smooth line $=$ single axle-air suspension, dotted line $=$ single axle steel suspension].
Vehicle speed $20 \mathrm{~m} / \mathrm{s}$

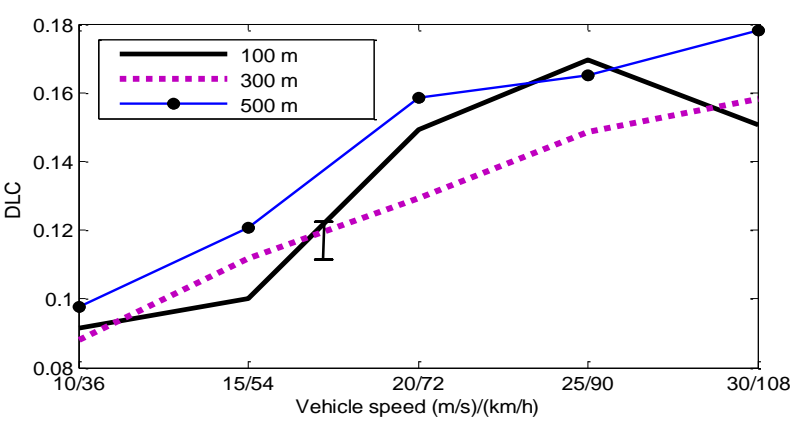

Fig. 3: DLCs of the forces from the STEER axles travelling on $100 \mathrm{~m}, 200 \mathrm{~m}$ and $500 \mathrm{~m}$ roads with the IRI value is 3.5

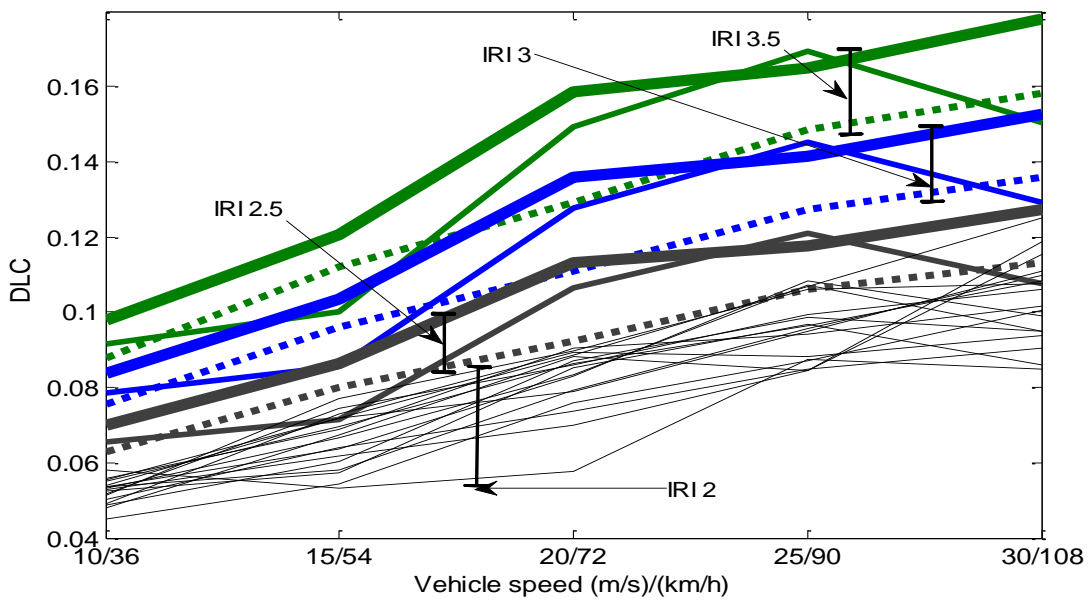

Fig. 4: DLCs of the forces from the STEER axles travelling at $100 \mathrm{~m}, 300 \mathrm{~m}$ and $500 \mathrm{~m}$ road with IRI 2 to 3.5 .

Table 4: Maximum DLC for all Quarter-truck models

\begin{tabular}{|c|c|c|c|c|}
\hline \multicolumn{5}{|c|}{$\mathrm{L}=100$} \\
\hline Q-TRUCK Model & DLC & $\begin{array}{l}\text { Loading } \\
\text { condition }\end{array}$ & $\begin{array}{c}\text { ROAD } \\
\text { PROFILE /IRI }\end{array}$ & $\begin{array}{l}\text { Truck } \\
\text { Speed }\end{array}$ \\
\hline STEER & 0.1694 & Full & \multirow{7}{*}{3.5} & \multirow{7}{*}{30} \\
\hline SINS & 0.4938 & \multirow{6}{*}{$1 / 3$} & & \\
\hline SINA & 0.3475 & & & \\
\hline DUAS & 0.7430 & & & \\
\hline DUAA & 0.5908 & & & \\
\hline TRIS & 0.7172 & & & \\
\hline TRIS & 0.4408 & & & \\
\hline \multicolumn{5}{|c|}{$\mathrm{L}=300$} \\
\hline Q-TRUCK Model & DLC & $\begin{array}{c}\text { Loading } \\
\text { condition }\end{array}$ & $\begin{array}{c}\text { ROAD } \\
\text { PROFILE /IRI }\end{array}$ & $\begin{array}{l}\text { Truck } \\
\text { Speed }\end{array}$ \\
\hline STEER & 0.1583 & Full & \multirow{7}{*}{3.5} & \multirow{7}{*}{30} \\
\hline SINS & 0.4963 & \multirow{6}{*}{$1 / 3$} & & \\
\hline SINA & 0.3696 & & & \\
\hline DUAS & 0.7546 & & & \\
\hline DUAA & 0.5938 & & & \\
\hline TRIS & 0.7257 & & & \\
\hline TRIA & 0.4411 & & & \\
\hline \multicolumn{5}{|c|}{$\mathrm{L}=500$} \\
\hline Q-TRUCK Model & DLC & $\begin{array}{l}\text { Loading } \\
\text { condition }\end{array}$ & $\begin{array}{c}\text { ROAD } \\
\text { PROFILE /IRI }\end{array}$ & $\begin{array}{l}\text { Truck } \\
\text { Speed }\end{array}$ \\
\hline STEER & 0.1780 & Full & \multirow{4}{*}{3.5} & \multirow{4}{*}{30} \\
\hline SINA & 0.3844 & \multirow{3}{*}{$1 / 3$} & & \\
\hline SINS & 0.4998 & & & \\
\hline DUAS & 0.7284 & & & \\
\hline
\end{tabular}




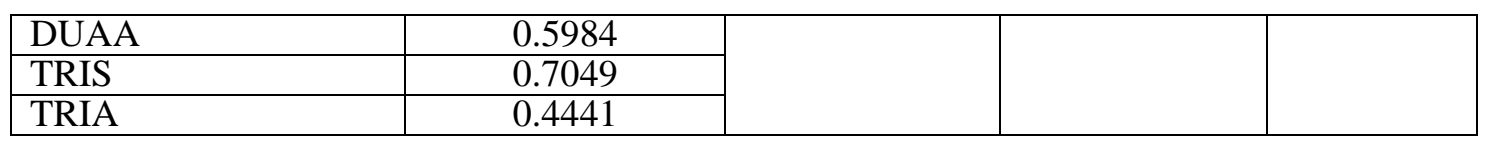

\section{Conclusion}

It can be concluded that a road with higher International roughness index value will automatically increase the axle loading and it might be worse when axle fitted with steel suspension rather than axle fitted with air suspension. Dynamic load generated by certain road profiles IRI $=2$ are more than $30 \%$ of its static load and about 50\% higher when road profiles IRI increased to 3.5 .

\section{Acknowledgement}

We are grateful for the Office for Research, Innovation, Commercialization and Consultancy Management (ORICC), UTHM for funding this research.

\section{References}

[1] Gyenes et al, 1992, The spatial repeatability of dynamic pavement load caused by heavy goods vehicles, Third Int. Symposium on Heavy vehicle weights and dimensions, UK, Thomas Telford.

[2] OECD, 1992, Dynamic Loading of Pavements, Paris.

[3] DIVINE, 1998, Dynamic interaction between vehicles and infrastructure experiment, Technical Report.

[4] Sun and Kennedy, 2007, Spectral analysis and parametric study of stochastic pavement loads, J. of Eng. Mech., vol. 128, pp. 318-327.

[5] Cebon D., 1999, Handbook of vehicle -road interaction, Taylor and Francis Group, England.

[6] Hardy, M. S. A., Cebon, D., 1994, Importance of speed and frequency in flexible pavement response", J. Eng. Mech. ASCE 120(3), pp. 463-482.

[7] Gillespie, T. D., Karamihas, S. M., Sayers, M. W., Nasim, M. A., Hansen, W., Ehsan N. and Cebon, D.,1993,Effects of heavy-vehicle characteristics on pavement response and performance. Report 353, TRB, Washington, District of Columbia.

[8] Buhari R. Puteh S., 2014, Damage equivalent of the flexible pavement variation with load applied, Applied Mechanics and Materials Vols. 405-408, Trans Tech Publications, Switzerland, pp: 1917-1922.

[9] Todd, K. B., Kulawowski, B. T., 1991, Simple computer models for predicting ride quality and pavement loading for heavy trucks, TRR No 1215: pp.137-150.

[10] Collop, A. C., 1994, Effect of traffic and temperature on flexible pavement wear, PhD thesis, Cambridge University Engineering Department, Cambridge UK.

[11] Sun, L., 2001, Computer simulation and field measurement of dynamic pavement loading, Mathematic and Computers in Simulation 56: pp. 297-313.

[12] Buhari R., Abdullah M.E, Rohani M, 2014, Predicting truck load variation using Q-truck model, Applied Mechanics and Materials., Trans Tech Publication, Switzerland,Vol. 534 (2014)pp 105-110.

[13] Buhari R., Rohani M, Abdullah M.E., 2014, Dynamic load coefficient of tyre forces from truck axles. Applied Mechanics and Materials, Trans Tech Publication, Switzerland,Vol. 534 (2014), pp 105-110. 